Participatory Educational Research (PER)

Vol. 2(2), pp. 59-69, August, 2015

Available online at http://www.partedres.com

ISSN: 2148-6123

http://dx.doi.org/10.17275/per.15.15.2.2

\title{
Cross-Gender Equivalence of Cyber Bullying and Victimization
}

\author{
Sirr1 Akbaba \\ Usküdar University, Psychology, Istanbul
}

Adem Peker*

Atatürk University, Guidance and Counseling, Erzurum

Yüksel Eroğlu

Bayburt University, Guidance and Counseling, Bayburt

\section{Erkan Yaman}

Sakarya University, Educational Sciences, Sakarya

\begin{tabular}{ll}
\hline \hline Article history & This study aims to investigate the cross-gender equivalency of \\
Received: & cyber bullying and victimization across gender using Revised \\
& Cyber Bullying Inventory (RCBI). Because gender differences may \\
Received in revised form: & have a strong effect on measurement inequalities, tests of \\
01.06 .2015 & measurement invariance were conducted to ensure that the scores \\
& obtained from cyber bullying and victimization forms of RCBI \\
Accepted: & were generalizable between males and females. The samples for \\
02.06 .2015 & this study consisted of 217 females and 235 males. The \\
Key words: & measurement invariance of the cyber bullying and victimization \\
\hline $\begin{array}{l}\text { Cyber bullying and } \\
\text { victimization, tests of } \\
\text { measurement invariance, multi- } \\
\text { group confirmatory factor } \\
\text { analysis }\end{array}$ & forms of RCBI was examined with multiple group confirmatory \\
& confirmatory factor analysis procedures were utilized. In order that \\
& collate relative fit of nested models across gender, change in CFI \\
& (comparative fit index) was utilized here, with a suggestion that \\
& support for the more parsimonious model can fit data better than a \\
& less parsimonius model requires a change in CFI is smaller or equal \\
& to .01. Confirmatory factor analyses were conducted using \\
& LISREL. MG-CFA results showed that there were not enough \\
& evidence to support the measurement invariance of the cyber \\
& bullying and victimization forms of RCBI across gender at a scale \\
& level. Results were discussed in the light of the literature.
\end{tabular}

\section{Introduction}

Bullying is often depicted as being an aggressive, intentional act or behavior that is done by individual or group repeatedly in order to humiliate victims who are inferior them,

\footnotetext{
"Correspondence: adem.peker@hotmail.com
} 
either physically or psychologically (Olweus 1999). With the rapid growth of communication and information technology, cyberspace has been implicated as a new risky environment for bullying. This new form of bullying called cyber bullying refers to bullying by the means of information and communication technologies such as emails, text messages, and web sites (Kowalski, Limber \& Agatston 2008). Cyber bullying is also delineated as repeated hostile behavior of an individual or a group toward another individual through communication technologies such as e-mail, cell phone, SMS, instant messaging, personal web sites, and blogs. Other terms may refer to cyber bullying include online bullying, e-bullying, digital bullying, internet bullying, and cyber harassment (Kowalski et al. 2008). Cyber bullying varies in forms and by means. Aricak and colleagues (2008) stated that cyber bullying includes online behaviors such as lying, hiding the identity, introducing oneself as someone else, threatening, teasing, insulting, defamation, intimidation, rumor, and displaying others' pictures without their consent in cyberspace.

Researches about cyber bullying indicate that cyber victims suffer academic problems such as absenteeism (Katzer, Fetchenhauer \& Belschak 2009) and lack of concentration (Beran \& Li 2007), and mental health problems such as depression (Ybarra, Alexander \& Mitchell 2005), social anxiety (Juvonen \& Gross 2008), low self-esteem (Katzer et al., 2009), substance use (Ybarra \& Mitchell, 2004), helplessness (Hinduja \& Patchin 2008), tendency to violate school rules (Ybarra, Diener-West \& Leaf 2007).

Cyber bullies suffer psychological problems as well as cyber victims. Cyber bullies feel extremely anger for no reason (Pornari \& Wood 2010) and feel hostility towards others (Arıcak 2009). Consequently, cyber bullies and cyber victims suffer from, and are at risk of mental health problems. Another significant point addressed in the researches is gender differences in cyber bullying and cyber victimization. Because cyber bullying has been considered as a part of relational bullying (Keith \& Martin 2005), researchers have found that females engage in cyber bullying more than males. However, researches in Turkey (Aricak et al., 2008; Dilmaç 2009; Erdur-Baker 2010; Erdur-Baker \& Kavşut 2007; Peker, Eroğlu \& Çitemel 2012) challenge the claim that girls are more likely to engage in cyber bullying.

It is seen that gender differences in cyber bullying and cyber victimization have typically been based on studies utilizing a mean difference method. From a measurement perspective, this method is inherently problematic unless cyber bullying and cyber victimization scales possesses comparable validity across gender. Stated differently, establishing measurement invariance on the measures of cyber bullying and cyber victimization is prerequisite to making any inferences about gender differences (Kim, Kim \& Kamphaus 2010). For this reason, whether cyber bullying and cyber victimization operates in the same way across gender is investigated using Revised Cyber Bullying Inventory (RCBI) in this study. Therefore, the issue of whether or not both cyber bullying and cyber victimization forms of RCBI are unbiased in relation to gender is assessed by multi-group confirmatory factor analysis (MG-CFA) which allows for the testing of a hypothesized factor structure in different groups simultaneously (MacCallum \& Austin 2000; Rijkeboer \& Bergh 2006). The reason of choosing RCBI as measurement tool is because it has largely utilized to determine gender differences in cyber bullying and cyber victimization (Çetin, Eroğlu, Peker, Akbaba \& Pepsoy 2012; Erdur-Baker \& Tanrıkulu 2009; Eroğlu 2011; Eroğlu, Çetin, Güler, Peker \& Pepsoy 2011; Mura, Topçu, Erdur-Baker \& Diamantini 2011; Topçu \& Erdur-Baker 2011) among cyber bullying and victimization scales (Akbulut \& Erişti 2011; Akbulut, Şahin \& Erişti 2010; Çetin, Yaman \& Peker 2011). 
Measurement invariance involves testing the equivalence of measured constructs in two or more independent groups to assure that the same constructs are being assessed in each group (Chen, Sousa, \& West 2005). From this perspective, it can be claimed that whether the underlying construct has the same theoretical structure across gender is given great attention in psychology. For example, considering moral reasoning, Gilligan (1997) claimed that men and women differ in their moral reasoning, so women consider ethic of care which highlights the interdependence of individuals as opposed to men who use ethic of justice which places on individual autonomous choice and equality (as cited in Akbaba 2009).

Measurement invariance is achieved when parameters of the measurement model are equivalent across groups (Tucker, Ozer, Lyubomirsky \& Boehm 2006). Methods which aim to test measurement invariance in the framework of EFA (explanatory factor analysis) focus only on similarity of factor patterns across groups. In contrast, testing for measurement invariance of CFA (confirmatory factor analysis) models addresses the configural invariance, metric invariance, scalar invariance, and the strict invariance of the model (Cheung \& Renswold 2002; Dimitrov 2010).

Configural invariance is defined as the same pattern of fixed and free factor loadings (and other parameters) across groups, but no equality constraints. The model of configural invariance serves as a useful baseline model to which researchers can compare more restrictive models (Meredith \& Teresi 2006). Criteria for metric measurement invariance are that equivalence of factor loadings across groups. Equivalence of factor loadings demonstrates that the latent variable is related to items in the same way across groups. Establishing equivalence at this level is importance because each item that is chosen to measure a latent variable should equally measure that latent variable across groups. Scalar invariance required equivalence of item intercepts across groups as well as equivalence of factor loadings. Item intercepts are the assets of the indicator scores when the latent variable is zero (Bayram 2010). Under scalar invariance, the comparison of factor groups is permissible.

The lack of equivalence of item intercepts across groups indicates the presence of item bias (Dimitrov 2010; Tucker et al. 2006). To compare group means on manifest variables, scalar invariance must be established (Tucker et al. 2006). A strict level of measurement is required equal factor loadings, equal item incepts, and equal item uniqueness (error variances and covariances) across groups. The invariance of item uniqueness across groups provides evidence that the items were measured with the same precision in each group. Meeting the criteria of strict measurement invariance indicates group differences on any item stem from entirely group differences on the common factors (Dimitrov 2010). Establishing measurement invariance involves a hierarchy of these stages as one will be the prerequisite for upper stage. In the event of testing measurement invariance, the first stage is to test for configural invariance that is to fit a baseline model for each group separately. The second step is to test for metric invariance using the data for all groups simultaneously in order to obtain more efficient parameter estimates. These two steps must precede testing for scalar invariance respectively (Dimitrov 2010). Last, to analyze strict invariance, configural, metric, and scalar invariance should be examined respectively and revealed (Güzeller 2011; Uzun \& Öğretmen 2010). 


\section{Method}

\section{Research Design}

The current study utilized a descriptive design, supported by the measurement theory and psychometric theory (Nunnally \& Bernstein, 1994) to cross gender validate the cyber bullying and victimization. Psychometric equivalency was inquired by examining the measurement invariance across gender.

\section{Study Group}

Participants were 452 (217 (48 \%) were female and 235 (52\%) were male) high school students from different high schools in Bursa. Their ages ranged from 15 to 18 $(\mathrm{M}=16.39, \mathrm{SD}=1.002)$.

\section{Instruments}

Revised Cyber Bullying Inventory [RCBI; 40] consists of 28 items, 14 of which are in cyber bullying form and 14 of which are in cyber victimization form. For each item, participants indicate their response using a 4-point likert type scale ranging from 1 (none) to 4 (more than three times). Exploratory factor analysis revealed that items in cyber bullying form loaded one factor loadings of items varied from .28 to .83. Confirmatory factor analysis showed that the model contained one factor was well fit. Goodness of fit indices were found as $\mathrm{GFI}=.93, \mathrm{AGFI}=.89, \mathrm{CFI}=.93, \mathrm{NFI}=.89$, $\mathrm{TLI}=.90$, and $\mathrm{RMSEA}=.06$. Like cyber bullying form, cyber victimization form includes a single factor and factor loadings of items in this form varied between .21 and .78. Confirmatory factor analysis showed that the model contained one factor was well fit and chi-square value $\left(\chi^{2} / \mathrm{df}=1.85\right)$ was significant. Goodness of fit indices were found as GFI=.93, $\mathrm{AGFI}=.90, \mathrm{CFI}=.89, \mathrm{NFI}=.84$, TLI=.86, and RMSEA=.06. For criterion-related validity, relationship between cyber bullying and traditional bullying was calculated as .45. Similarly, relationship between cyber victimization and traditional victimization was found as .36. The more individual's score in RCBI increase, the more cyber bullying experiences increase. Similarly the more individual's score in RCBI increase, the more cyber victimization experiences increase.

\section{Procedures}

Data were collected during the fall semester of the 2014 school year. After obtaining school authority's permission from these five schools, a demographics form and RCBI were administered to the students during regular class time. The entire survey process, including informed consent, required approximately 10 minutes. The survey applied anonymously and all completed data were maintained in a secure location.

\section{Data Analysis}

To test for the measurement invariance of cyber bullying and cyber victimization form of RCBI, several multiple-group confirmatory factor analyses were conducted using LISREL 8.54 (Jöreskog \& Sorbom 1996). The items of cyber bullying and cyber victimization form of RCBI were treated as continuous variables and the maximum likelihood estimation (ML) were used both confirmatory and multi-group confirmatory factor analysis because the data were multivariate normally distributed. Moreover, the skewness and kurtosis estimates divided by the standard error all not exceeded a z-score of 1.96 and indicated the data were normally distributed thereby reinforcing the selection of the ML estimator for invariance analysis. 
Confirmatory factor analyses were used to examine the dimensional structure of the cyber bullying and cyber victimization form of RCBI in females and males sample simultaneously. Covariance matrix was adopted as input. Several goodness-of-fit indices were used to evaluate the fit of the models to the data, including chi-square/degree of freedom $\left(\chi^{2} / \mathrm{df}\right)$, root mean square error of approximation (RMSEA), comparative fit index (CFI), and non-normed fit indices (NNFI). For $\chi^{2} / \mathrm{df}$, values $\leq 2$ indicate perfect fit, values $\leq 5$ indicate acceptable fit. The CFI and NNFI, vary along a 0 -to- 1 continuum, in which values greater than .90 and .95 are taken to indicate acceptable and perfect fits to the data, respectively. In relation to RMSEA indices, values $\leq .08$ demonstrate acceptable fit, and values $\leq .05$ demonstrate excellent fit (Hu \& Bentler 2004; Kline 2005).

To investigate whether the aspects of factor structure would systematically hold invariant across females and males, analyses were done by hierarchically nesting the models to conduct systematic comparison test (Vandenberg \& Lance 2000; Huang, Zhou, Wang \& Zhang 2010). Namely, testing for factorial invariance of confirmatory factor analysis is substantiated by testing sequence of models, beginning with an unconstrained model and progressively introducing equality constraints on parameters (Vandenberg \& Lance 2000). The following hierarchical ordering of nested models was tested to reflect the relative importance of the different sets of parameters: (a) unconstrained model, (b) factor loadings invariant, (c) factor loadings and error variances invariant across groups, (d) factor loadings, error variance and factor correlations invariant (Brown 2006; Çetin 2010; Şekercioğlu 2010; Wang, Willett \& Eccles 2011).

In order to compare relative fit of nested models, change in CFI ( $\underline{\Delta} \mathrm{CFI})$ was used here, with a recommendation that support for the more parsimonious model (the more highly constrained model with fewer estimated parameters) can fit data better than a less parsimonious model requires a change in CFI is smaller or equal to .01 (Cheung \& Rensvold 2002).

\section{Results}

Table 1 demonstrates the reliabilities within each sample for cyber bullying and cyber victimization form. Both cyber bullying and cyber victimization forms displayed highly satisfactory internal consistencies in each gender. Cyber bullying form appeared to have higher reliabilities than cyber victimization form in each gender.

Table 1. Reliabilities (Cronbach's Alpha) of Cyber Bullying and Cyber Victimization Forms in Each Gender

\begin{tabular}{ccc}
\hline Gender & cyber victimization & cyber bullying \\
\hline Male & .83 & .86 \\
Female & .82 & .85 \\
\hline
\end{tabular}

Firstly, confirmatory factor analysis was done using total group sample $(\mathrm{N}=452)$, consists males and females, as a preliminary both cyber victimization and cyber bullying forms of RCBI. For cyber victimization form, this a priori model did not provide acceptable goodness of fit indices, in accordance with current proposed standards. Therefore, the modification indices suggested a substantial improvement in fit associated with freeing the correlation of the error variance between item 1 and item 6, item 2 and item 14, item 3 and item 11, item 3 and item 5, item 4 and item 5, item 4 and item 6, item 4 and item 12, item 6 and item 8, item 7 and item 14, item 7 and item 9, item 9 and item 13, item 10 and item 11, item 11 and item 13 (Bayram 2010; Huang et al. 2010). The model fit was significantly improved after using 
modification indices. The overall fitness indices of modified model were $\chi^{2} / \mathrm{df}=2.24$, RMSEA $=.053, \mathrm{CFI}=0.98, \mathrm{NNFI}=0.97$, which indicates that the model was excellent fit. The fit indices of model with and without modification indices are presented in Table 2. For cyber bullying form, this initial model did not show acceptable fit to the data and substantially improved using modification indices between the errors of item 1 and item 11, the errors of item 2 and item 9, the errors of item 3 and item 4, the errors of item 3 and item 9, the errors of item 6 and item 9, the errors of item 6 and item 13, the errors of item 8 and item 9, the errors of item 9 and item 11, the errors of item 10 and item 11, the errors of item 10 and item 13, the errors of item 11 and item 12, the errors of item 12 and item 14. There was not acceptable fit with the initial model, but the goodness-of-fit indices of the respecified model improved excellently with respect to goodness-of-fit indices of the initial model (see Table 2). Secondly, a priori model to fit data separately, for each of males and females with no invariance constraints, were tested.

Table 2. Goodness-of-fit-indices for Different Models in Total, Male, and Female Samples for Cyber Victimization and Cyber Bullying

\begin{tabular}{|c|c|c|c|c|}
\hline Models & $\chi^{2} / \mathrm{df}$ & RMSEA $(90 \% \mathrm{CI})$ & CFI & NNFI \\
\hline \multicolumn{5}{|l|}{$\mathrm{CV}$} \\
\hline \multicolumn{5}{|l|}{ Total sample } \\
\hline Initial model & 8.91 & $0.13(0.12 ; 0.14)$ & 0.83 & 0.80 \\
\hline Modified model & 2.24 & $0.053(0.041 ; 0.064)$ & 0.98 & 0.97 \\
\hline \multicolumn{5}{|l|}{ Male sample } \\
\hline Initial model & 3.003 & $0.122(0.10 ; 0.14)$ & 0.85 & 0.82 \\
\hline Modified model & 1.91 & $0.079(0.061 ; 0.10)$ & 0.93 & 0.91 \\
\hline \multicolumn{5}{|l|}{ Female sample } \\
\hline Initial model & 7.19 & $0.14(0.13 ; 0.15)$ & 0.85 & 0.82 \\
\hline Modified model & 1.83 & $0.052(0.036 ; 0.067)$ & 0.98 & 0.97 \\
\hline \multicolumn{5}{|l|}{$\mathrm{CB}$} \\
\hline \multicolumn{5}{|l|}{ Total Sample } \\
\hline Initial model & 6.90 & $0.11(0.11 ; 0.12)$ & 0.91 & 0.89 \\
\hline Modified model & 2.45 & $0.057(0.046 ; 0.068)$ & 0.98 & 0.97 \\
\hline \multicolumn{5}{|l|}{ Males } \\
\hline Initial model & 3.50 & $0.137(0.12 ; 0.15)$ & 0.86 & 0.84 \\
\hline Modified model & 1.77 & $0.076(.053 ; 0.098)$ & 0.96 & 0.94 \\
\hline \multicolumn{5}{|l|}{ Females } \\
\hline Initial model & 7.40 & $0.14(0.13 ; 0.15)$ & 0.87 & 0.84 \\
\hline Modified model & 2.27 & $0.063(0.049 ; 0.078)$ & 0.98 & 0.97 \\
\hline
\end{tabular}

Note: $\mathrm{CV}=$ Cyber Victimization; $\mathrm{CB}=$ Cyber Bullying; $\mathrm{CI}=$ Confidence Interval; RMSEA=Root Mean Square Error of Approximation; CFI=Comparative Fit Index; NNFI=Non-Normed Fit Indices; $\chi^{2} / \mathrm{df}=$ chi-square/degree of freedom ratio

As seen in Table 2, initial CFA models for cyber bullying did not have acceptable fit in males and females as well as initial CFA models for cyber victimization. Therefore, the initial models for cyber bullying and cyber victimization in both males and females were improved by correlating error variances as recommended by the all modification indices, and then it was seen that the modified CFA models of cyber bullying and cyber victimization in both of genders were well fit in relation to previously mentioned standards for acceptable fit.

Table 3 summarizes the results of measurement invariance of the model across genders for cyber victimization. Evaluating measurement invariance was started with the baseline model, in which all parameters are free across gender (Model 1 in Table 3). Model 1 is vital, because all other models with invariance constrained, are nested under this model. So Model 1 gives a crucial starting point, for comparing the influence of other invariance constraints. If it will 
result that a more parsimonious solution with invariance constraints is able to fit the data, there is support for the invariance constraints (Çetin 2010). The baseline model did not yield an acceptable absolute fit, implying that configural invariance of the model does not hold across genders. Hence testing for model invariance which involves using the forward sequential procedures described in introduction is not conducted.

Table 3. Goodness of Fit in Confirmatory Factor Model across Gender for Cyber Victimization

\begin{tabular}{llllll}
\hline MODEL & $\chi^{2} / \mathrm{df}$ & $\begin{array}{l}\text { RMSEA }(90 \% \\
\text { CI })\end{array}$ & CFI & NNFI & \multirow{2}{*}{ CFI } \\
\hline Model 1 $^{\mathrm{a}}$ & 15.05 & $0.19(0.18 ; 0.20)$ & 0.78 & 0.74 & \\
Model 2 $^{\mathrm{b}}$ & 12.71 & $0.20(0.19 ; 0.21)$ & 0.74 & 0.71 & -.03 \\
Model 3 $^{\mathrm{c}}$ & 14.62 & $0.21(0.21 ; 0.22)$ & 0.68 & 0.68 & -.06 \\
Model 4 $^{\mathrm{d}}$ & 14.55 & $0.21(0.21 ; 0.22)$ & 0.68 & 0.68 & -.06 \\
\hline
\end{tabular}

Note: $:^{\mathrm{a}}$ Unconstrained ${ }^{\mathrm{b}}$ Factor Loadings Invariant ${ }^{\mathrm{c}}$ Factor Loadings and error variances Invariant ${ }^{\mathrm{d}}$ Factor Loadings, error variances and factor correlations invariant.

Table 4 contains the fit statistics for the four nested models and indicates that CFA in each group did not provide evidence of configural invariance for boys and girls. Thus further testing was not performed. Because evidence of configural invariance is prerequisite for measurement invariance, further testing is not appropriate if configural invariance does not hold (Cheung \& Rensvold 2002).

Table 4. Goodness of Fit in Confirmatory Factor Model Across Gender for Cyber Bullying

\begin{tabular}{llllll}
\hline MODEL & $\chi^{2} / \mathrm{df}$ & $\begin{array}{l}\text { RMSEA }(90 \% \\
\text { CI })\end{array}$ & CFI & NNFI & $\underline{\Delta}$ CFI \\
\hline Model 1 $^{\mathrm{a}}$ & 7.31 & $0.15(0.14 ; 0.15)$ & 0.83 & 0.79 & \\
Model 2 $^{\mathrm{b}}$ & 7.82 & $0.15(0.14 ; 0.16)$ & 0.80 & 0.78 & -.03 \\
Model 3 $^{\mathrm{c}}$ & 15.67 & $0.22(0.21 ; 0.23)$ & 0.32 & 0.32 & -.51 \\
Model 4 $^{\mathrm{d}}$ & 15.40 & $0.22(0.21 ; 0.23)$ & 0.31 & 0.31 & -.52 \\
\hline
\end{tabular}

Note: ${ }^{\mathrm{a}}$ Unconstrained ${ }^{\mathrm{b}}$ Factor Loadings Invariant ${ }^{\mathrm{c}}$ Factor Loadings and error variances Invariant ${ }^{\mathrm{d}}$ Factor Loadings, error variances and factor correlations invariant.

\section{Discussion and Conclusion}

In this study, the cross-gender measurement invariance of cyber bullying and cyber victimization form of RCBI were examined. Accordingly, first of all, CFAs were conducted with total sample as well as each gender separately. In this study, the results of study indicated that neither models of cyber bullying nor of cyber victimization show well fit in female, male and total samples on all fit indices except for CFI in boy's group exceeding the cut-off value of .90 . Therefore models of cyber bullying and cyber victimization in female, male, and total sample substantially were improved by using modification indices only when suggested modifications are valid conceptually. After that internal consistency coefficients were calculated for both cyber bullying and cyber victimization forms by gender separately. Results showed that both cyber bullying and cyber victimization forms yielded satisfactory reliability coefficients.

An important feature of this research is examination of the cross-gender measurement invariance of the cyber bullying and cyber victimization forms of RCBI. For this purpose, four different CFA models were used, ranging from an unconstrained model to most constrained model, in terms of parameter estimations. In addition to the foregoing, there are 
some general constraints which are common for these four models, such as item intercepts, associated with each item, were not allowed to be correlated with item intercepts for any other items (Çetin 2010). Tests of measurement invariance began with testing configural invariance both for cyber bullying and cyber victimization forms of RCBI and the baseline models of cyber bullying and cyber victimization testing configural invariance of the proposed model did not show acceptable fit. This means that it can be said that unconstrained models of cyber bullying and cyber victimization failed to meet criteria for adequate goodness of fit indices, indicating that a one-factor model for cyber bullying and cyber victimization forms of RCBI did not hold for both gender. In other words, different constructs were measured across gender.

The failure to meet criteria for the unconstrained model in testing for measurement invariance across gender may be due to differences in interpretations and conceptualizations of the items on the cyber bullying and cyber victimization form of the RCBI. Specifically, differences in what behaviors are considered to be cyber bullying as well as in level of awareness about behaviors related cyber bullying, might have influenced responses to some of the items, thus serving as a barrier to meeting criteria for measurement invariance (Tucker et al. 2006). These interpretations are consistent with findings from previous studies, including those from Keith and Martin (2005)'s study, suggesting that comparing males, females may perceive behaviors aimed at damaging social relationships as cyber bullying instead of threating and insulting peoples on the internet. It can be suggested that easy way to resolve this problem is researchers can conceptualize cyber bullying as multidimensional rather than one-dimensional pattern. Moreover Erdur-Baker (2010) claimed that females and males have different perceptions of risky internet usage and girls are becoming more cautious about cyber bullying because girls in Turkey are raised under close supervision and taught to be more selfconscious. Also cultural tolerance for more aggressive behavior in males may have led to the failure to meet criteria for the baseline model when comparing males and females. Thus, males may have been overly engaged in thoughts that their aggressive behaviors unrelated to cyber bullying is offered in a normal and non-threating manner and enables themselves to express ways of feelings and ideas.

Several limitations to this study should be noted. The major limitation of this study is source of the problem in meeting criteria for the baseline model when comparing males and females. It is still unclear whether the failure to establish configural invariance is stem from the content of the items, or characteristics of the sample. Hereby, it is difficult to determine whether lack of fit for baseline model may have been due to differences in testing conditions or differences between the characteristics of males and females (e.g., understanding what behaviors are considered to be cyber bullying, differences awareness of cyber bullying, broadened cultural tolerance for aggressive behaviors in males). Secondly, because this research focuses on adolescents, the generalizability of this results to other groups and is limited. In future research, it will be important to investigate the measurement invariance of scales measuring cyber bullying and cyber victimization with more varied groups such as internet addicts and non-addicts. In this study, multi-group confirmatory factor analysis was utilized to investigate the parameter invariance of scale structures in cross-gender measurement invariance studies. For this reason, there should be future research to determine the reasons why cyber bullying and cyber victimization forms of RCBI are not free of gender-related measurement bias by using different methods. Even with these limitations in mind, the current study is significant in that it is, to our knowledge, the only research that investigated the measurement invariance of such scale measuring cyber victimization and cyber bullying. The information provided by this study may contribute to cyber bullying and cyber victimization literature and may be 
provided as a guide for researchers interested in developing measurement tools about cyber bullying and cyber victimization.

\section{References}

Akbaba, S. (2009). Ahlak ve gelişimi. In Y. Özbay \& S.Erkan (Eds.), Eğitim Psikolojisi (pp.165-203). Ankara: Pegem Akademi.

Akbulut, Y., \& Erişti, B. (2011). Cyberbullying and victimization among Turkish university students. Australasian Journal of Educational Technology, 27(7), 1155-1170.

Akbulut, Y., Şahin, Y.L., \& Erişti, B. (2010). Development of a scale to investigate cybervictimization among online social utility members. Contemporary Educational Technology, 1(1), 46-59.

Arıcak, O.T. (2009). Psychiatric symptomatology as a predictor of cyberbullying among university students. Eurasian Journal of Educational Research, 34, 167-184.

Arıcak, T., Siyahhan, S., Uzunhasanoğlu, A., Sarıbeyoğlu, S., Çıplak, S., Yılmaz, N., et al. (2008). Cyberbullying among Turkish adolescents. CyberPsychology \& Behavior, 11(3), 253-262.

Bayram, N. (2010). Yapısal eşitlik modellemesine giriş amos uygulamalari. Bursa: Ezgi Kitabevi.

Beran, L., \& Li, Q. (2007). The relationship between cyberbullying and school bullying. Journal of Student Wellbeing, 1, 15-33.

Brown, T.A. (2006). Confirmatory factor analysis for applied research. New York: The Guilford Press.

Chen, F.F., Sousa, K.H., \& West, S.G. (2005). Testing measurement invariance of secondorder factor models. Structural Equation Modeling, 12, 471-492.

Cheung, G.W., \& Rensvold, R.B. (2002). Evaluating goodness-of-fit indexes for testing MI. Structural Equation Modeling, 9, 235-55.

Çetin, B. (2010). Cross-cultural structural parameter invariance on PISA 2006 student questionnaires. Eurasian Journal of Educational Research, 38, 71-89.

Çetin, B., Yaman, E., \& Peker, A. (2011). Cyber victim and bullying scale: A study of validity and reliability. Computers \& Education, 57(4), 2261-2271.

Çetin, B., Eroğlu, Y., Peker, A., Akbaba, S., \& Pepsoy, S. (2012). The investigation of relationship among relational-interdependent self-construal, cyberbullying, and psychological disharmony in adolescents: An Investigation of Structural Equation Modelling. Educational Sciences: Theory \& Practice, 12(2), 646-653.

Dilmaç, B. (2009). Psychological needs as a predictor of cyber bullying: A preliminary report on college students. Educational Sciences: Theory \& Practice, 9, 1291-1325.

Dimitrov, D.M. (2010). Testing for factorial invariance in the context of construct validation. Measurement and Evaluation in Counseling and Development, 43, 121-149.

Erdur-Baker, Ö. (2010). Cyberbullying and its correlation to traditional bullying, gender, and frequent and risky usage of internet-mediated communication tools. New Media \& Society, 12(1), 109-125.

Erdur-Baker, Ö., \& Kavşut, F. (2007). Cyberbullying: A new face of peer bullying. Eurasian Journal of Educational Research, 27, 31-42.

Erdur-Baker, Ö., \& Tanrıkulu, İ. (2009). Cyber bullying in Turkey: Its correlates and links to depressive symptoms. Journal of eHealth Techology and Application, 7, 16-23.

Eroğlu, Y. (2011). The investigation relationships among contingencies of self-worth, risky internet behaviors, and cyberbullying/cybervictimization. Unpublished master thesis, Sakarya University, Institute of Educational Sciences, Sakarya. 
Eroğlu, Y., Çetin, B., Güler, N., Peker, A., \& Pepsoy, S. (2011). From cybervictimization to coping ways of stress: Gender as moderator. Proceedings of EDULEARN11 Conference, 2699-2707.

Güzeller, C.O. (2011). A study of cross-cultural equivalence of computer attitude in PISA 2009 student questionnaire. Education and Science, 36, 320-327.

Hinduja, S., \& Patchin, J.W. (2008). Cyberbullying: An exploratory analysis of factors related to offending to victimization. Deviant Behavior, 29, 129-156.

Hu, L., \& Bentler, P.M. (2004). Cutoff criteria for fit indexes in covariance structure analysis: Conventional criteria versus new alternatives. Structural Equation Modeling, 6, 1-55.

Huang, D., Zhou, M., Wang, L., \& Zhang, J. (2010). Gender difference in motives of knowledge searching: Measurement invariance and factor mean comparisons of the interest/deprivation epistemic curiosity. Proceedings of 2010 IEEE $2^{\text {nd }}$ Symposium on Web Society, 258-264.

Jöreskog, K.G., \& Sorbom, D. (1996). LISREL 8 reference guide. Lincolnwood, IL: Scientific Software International.

Juvonen, J., \& Gross, E.F. (2008). Extending the school grounds? Bullying experiences in cyberspace. Journal of School Health, 78, 496-505.

Katzer, C., Fetchenhauer, D., \& Belschak, F. (2009). Cyberbullying: Who are the victims? A comparison of victimization in Internet chatrooms and victimization in school. Journal of Media Psychology, 21, 25-36.

Keith, S., \& Martin, M.E. (2005). Cyber bullying: Creating a culture of respect in a cyberworld. Reclaiming Children and Youth, 13, 224-228.

Kim, S., Kim, S.H., \& Kamphaus, R.W. (2010). Is aggression the same for boys and girls? Measurement invariance with confirmatory factor analysis and item response theory. School Psychology Quarterly, 25, 45-61.

Kline, R.B. (2005). Principles and practice of structural equation modeling. New York: The Guilford Press.

Kowalski, R.M., Limber, P., \& Agatston, P.W. (2008). Cyberbullying: Bullying in the digital age. New York: Blackwell Publishing.

MacCallum, R.C., \& Austin, J.T. (2000). Applications of structural equation modeling in psychological research. Annual Review of Psychology, 51, 201-226.

Meredith, W., \& Teresi, J. (2006). An essay on measurement and factorial invariance. Medical Care, 44, 69-77.

Mura, G.,Topçu, Ç., Erdur-Baker, Ö., \& Diamantini, D. (2011). An international study of cyber bullying perception and diffusion among adolescents. Procedia-Social and Behavioral Sciences, 15, 3805-3809.

Nunnally, J.C., \& Bernstein, I.H. (1994). Psychometric theory $\left(3^{\text {rd }}\right.$ ed.). New York: McGrawHill.

Olweus, D. (1999). Sweeden. In P.K. Smith, Y. Morita, J. Junger-Tas, D. Olweus, R. Catalano \& P.Slee (Eds.). The nature of school bullying: A cross national perspective (pp.7-27). New York: Routledge.

Peker, A., Eroğlu, Y., \& Çitemel, N. (2012). Relationship of submissive behavior and cyberbullying /cybervictimization: The mediation role of gender. International Journal of Human Sciences, 9(1), 205-221.

Pornari, D., \& Wood, J. (2010). Peer and cyber aggression in secondary school students: The role of moral disengagement, hostile attribution bias, and outcome expectancies. Aggressive Behavior, 36, 81-94.

Rijkeboer, M.M., \& Bergh, H. (2006). Multiple group confirmatory factor analysis of the young schema-questionnaire in a dutch clinical versus non-clinical population. Cognitive Therapy and Research, 30, 263-277. 
Şekercioğlu, G. (2010). Adaptation of self-perception profile for children and testing factor structure equation according to different variables. Unpublished doctoral dissertation thesis, Ankara University, Faculty of Education Sciences, Ankara.

Topçu, Ç., \& Erdur-Baker, Ö. (2010). The revised cyber bullying inventory (RCBI): Validity and reliability studies. Procedia Social and Behavioral Sciences, 5, 660-664.

Topçu, Ç., \& Erdur-Baker, Ö. (2011, February). Cyber bullying and gender: Mediator and moderator role of emphaty. $1^{\text {st }}$ EERA Spring School on Advanced Method in Educational Research. Dortmund: Institute for School Development Research.

Tucker, K.L., Ozer, D. J., Lyubomirsky, S., \& Boehm, J.K. (2006). Testing for measurement invariance in the Satisfaction with Life Scale: A comparison of Russians and North Americans. Social Indicators Research, 78, 341-360.

Uzun, B., \& Öğretmen, T. (2010). Assesing the measurement invariance of factors that are related to students' science achievement across gender in TIMSS-R Turkey Sample. Education and Science, 35, 26-35.

Vandenberg, R.J., \& Lance, C.E. (2000). A review and synthesis of the measurement invariance literature: suggestions, practices, and recommendations for organizational research. Organizational Research Methods, 3(1), 4-70.

Wang, M.T., Willett, J.B., \& Eccles, J.S. (2011). The assessment of school engagement: Examining dimensionality and measurement invariance across gender and race/ethnicity. Journal of School Psychology, 49, 465-480.

Ybarra, M.L., Alexander, C., \& Mitchell, K.J. (2005). Depressive symptomatology, youth internet use, and online interactions: A national survey. Journal of Adolescent Health, 36, 9-18.

Ybarra, M.L., Diener-West, M., \& Leaf, P.J. (2007). Examining the overlap in internet harassment and school bullying: Implications for school intervention. Journal of Adolescent Health, 41, 42-50.

Ybarra, L.M., \& Mitchell, K.J. (2004). Online aggressor/targets, aggressors, and targets: A comparison of associated youth characteristics. Journal of Child Psychology and Psychiatry, 45, 1308-1316. 